\title{
Dispositional and situational moral emotions, bullying and prosocial behavior in adolescence
}

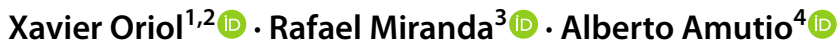

Accepted: 10 October 2021

(c) The Author(s) 2021

\begin{abstract}
Studies that distinguish the role of dispositional and situational moral emotions in bullying situations remain limited in the international literature. This work, therefore, aims to analyze the role of dispositional and situational moral emotions in bullying and prosocial behavior in adolescents. Two studies were conducted: a cross-sectional study including 644 adolescents aged 14-18 years $(M=15.6, D T=1.4)$ and a repeated measures design including 235 adolescents aged $10-15$ years $(M=12.5$, $D T=0.9$ ). The objectives of Study 1 were 1) to validate two scales for the situational moral emotions elicited in bullying situations (elevation and moral disgust) and 2) to examine the relationships between dispositional and situational moral emotions and prosocial behavior toward victims and bullying behavior. The results show adequate psychometric properties for both elevation and moral disgust scales. Furthermore, both situational moral emotions are negatively related to bullying behavior, whereas dispositional emotions such as compassion and gratitude have a positive effect on prosocial behavior. Study 2 assessed the prospective relationship between dispositional gratitude and prosocial behavior toward victims and bullying behavior. The results of this study indicate that dispositional gratitude has a positive prospective effect on prosocial behavior towards victims and a negative effect on bullying behavior. In conclusion, the relevance of moral emotions for the prevention of bullying behavior is highlighted and the role that self-transcendent dispositional emotions have on prosocial behavior from the perspective of developmental psychology.
\end{abstract}

Keywords Moral disgust and elevation in bullying situations · Dispositional gratitude and compassion · Prosocial behavior toward victims $\cdot$ Bullying behavior

\section{Introduction}

Bullying is considered a form of interpersonal violence that affect children and adolescents. Due to its high prevalence and negative consequences on mental and physical health, it has become a worldwide public health problem (Oriol et al., 2019). For example, a study conducted in more than

Xavier Oriol

xavier.oriol@udg.edu

1 Research Institute on Quality of Life, University of Girona, Girona, Spain

2 Department of Psychology, University of Girona, Plaça Sant Domènec, 917004 Girona, Spain

3 Department of Psychology, Universidad Continental, Lima, Perú

4 Department of Social Psychology and Methodology, Universidad del País Vasco, Leioa, Spain
70 countries found that approximately $30 \%$ of young adolescents are victims of bullying (Elgar et al., 2015).

One of the traits associated with bullying is moral disengagement, which is linked to apathy or indifference to bullying-related actions, whether from a bystander or an aggressor (Bandura, 2016; de Oliveira et al., 2019). In addition, moral disengagement in bullying cases has been related to low scores in consideration of others and poor self-control (García-Vázquez et al., 2020). In this line, a longitudinal study by Thornberg et al. (2019) including elementary students revealed that changes in moral disengagement altered the bullying behavior and increased the collective efficacy of the class, which stopped aggression towards other students.

The influence of moral disconnection on the development of aggressive and bystander behavior in bullying cases has led to an increase in studies on the association between the moral development of children and adolescents and interpersonal violence (Malti et al., 2020; Romera et al., 2019). In this sense, as children interact socially with other people, 
they learn social norms and experience moral emotions that allow them to judge transgressions and moral violations as wrong (Malti \& Ongley, 2014). Therefore, different studies have focused on how the experience of some moral emotions in social situations predicts higher levels of prosocial behavior and low levels of antisocial behavior in children and adolescents (Malti et al., 2020; Mazzone et al., 2019). However, and despite the growth in interest, many other moral emotions need to be studied, especially those in the taxonomy of moral emotions proposed by Haidt (2007). Furthermore, there is open debate at the international level on the evaluation of these moral emotions in specific social situations or as more stable and dispositional behaviors (Malti et al., 2020; Stellar et al., 2017). Moral emotions such as gratitude and compassion are commonly studied as dispositional emotions in different fields, but they have not been studied much in bullied adolescents (Rey et al., 2019; Zeng et al., 2020).

\section{Bullying and its Repercussions in Adolescence}

Bullying is a multidimensional phenomenon that occurs when harassment actions leading to relationships based on a victim-bully imbalance are present among peers (Oriol et al., 2019). The search for roles in the social hierarchy of peer groups during adolescence promotes the existence of bystanders, who also play a major role in the perpetuation or prevention of the phenomenon (Miranda et al., 2019; Wolke \& Lereya, 2015).

Several studies have classified the different forms of violence suffered by victims of bullying into traditional bullying (verbal, physical, or other forms of aggression that imply exclusion from the peer group) and cyberbullying (inflicted through electronic means) (Charalampous et al., 2020; Ortega-Ruiz et al., 2016). Bullying is currently one of the most complex phenomena studied in the school context due to its strong social impact on the normal development of children and adolescents (Hong \& Espelage, 2012). Specifically, during the adolescent period, due to the importance of the relationship between young people and their peer group in the formation of social identity, adolescents may be more likely to engage in bullying either as aggressors, victims, or bystanders, with devastating repercussions on their mental health (Modecki et al., 2014; Smokowski \& Evans, 2019).

The prevalence of bullying varies across countries; however, estimates show a presence of approximately $15 \%$ cyberbullying and 35\% traditional bullying (Modecki et al., 2014). Data confirm that this phenomenon has been acknowledged as a public health concern because it promotes physical health problems, anxiety, depression, increased suicide risk, poor school performance, and future aggressive behavior in victims, aggressors, and bystanders (Flannery et al., 2016). In this line, a meta-analysis based on 317 articles reviewed by Moore et al. (2017) confirmed that being a victim of bullying in adolescence can lead to different mental health problems, such as depression, anxiety, and even suicidal ideation, and physical health problems.

Nevertheless, mental health problems associated with bullying not only affects the victims but the bullies themselves. On many occasions, bullies have been victims of domestic violence and present more externalizing problems such as external anguish and consumption of toxic substances, whereas victims of bullying exhibit more internalizing problems such as loneliness and depression (Arseneault, 2017; Ttofi et al., 2014). Additionally, in general, bullies present lower levels of social and emotional skills compared to students not involved in bullying practices (Zych et al., 2018).

The consequences of bullying differ depending on age (Barlett \& Coyne, 2014). For example, a study by Cook et al. (2010) observed that adolescents who suffered bullying experienced more internalizing problems than other children in similar situations. However, the prevalence of bullying varies by age and, therefore, observing the behavior of this type of interpersonal victimization during different development stages is essential (Hymel \& Swearer, 2015). Particularly, it should be considered that the peak of bullying occurs in adolescence and the prevalence of the phenomenon decreases progressively in late adolescence (Currie et al., 2012; Miranda et al., 2019), while prosocial behavior increases at this time. This fact points to the relevance of promoting prosociality in advance in order to prevent bullying behaviors (Jungert et al., 2020; Van der Graaff, et al., 2018).

\section{Moral Emotions as Protective Factors Associated with Bullying Phenomena}

In research on bullying, key aspects to focus on are protective factors that may contribute to its prevention (Miranda et al., 2019; Zych et al., 2019). Researchers have focused on understanding how moral emotions can play a key role in preventing forms of violence such as bullying (e.g., Malti \& Latzko, 2010; Spinrad \& Eisenberg, 2019). There are multiple approaches to the development of moral emotions from childhood to adolescence (for a review, see Romera et al., 2019). For example, one of the most studied approaches is that proposed by Eisenberg (2000), whose studies have focused on the development of moral emotions and prosocial behavior from an early age. This perspective emphasizes the evolving influence of the "self" in relation to others from an early age and the development of moral emotions such as empathy, sympathy, or guilt (Spinrad \& Eisenberg, 2017, 2019). According to Spinrad and Eisenberg (2019), empathy involves affective processes that allow people to understand the emotional state of others, whereas sympathy implies cognitive processes such as feeling concerned about 
other people. These affective processes, especially cognitive processes in which sympathy is involved, have shown a strong relationship with the development of prosocial behavior through the understanding of the affective consequences that these actions have for oneself and others (Malti et al., 2020; Spinrad \& Eisenberg, 2019).

Malti and Latzko (2010) also proposed an approach to emotions and their relationship with cognitive development in childhood. Their perspective emphasizes the relevance of eliciting moral emotions in social contexts according to moral principles such as benefit to others, fairness, and justice (Malti et al., 2016). As in the perspective of the study by Eisenberg (2000), they also emphasized that these types of emotions, unlike other more basic ones, require cognitive processes and self-reflection that promote awareness of affective consequences for the self and for others (Malti \& Dys, 2015). Therefore, recently, Malti et al. (2019) classified these emotions according to their orientation, considering whether they are more focused on satisfying one's self or on promoting the well-being of others (self-oriented emotions "pride and guilt" vs. other-oriented emotions "respect and sympathy"). They also categorize moral emotions by their valence (positive, if the social situation is aligned with one's own moral principles, or negative, if the social situation transgresses one's own moral principles (Malti et al., 2019).

Many of the studies that associate moral emotions to bullying consider the experiences of some of the emotions in both bullies and bystanders. For example, in bystanders, the experience of guilt and the perception of transgressing moral norms in bullying situations seem to contribute to prosocial behavior toward victims (Barón et al., 2018; Sainio et al., 2011). In the same line, Thornberg et al. (2015) found that primary school students who scored high in empathy, sympathy, and guilt also exhibited anti-bullying behavior (i.e., defended the victims), and such emotions implied an awareness of the negative consequences for the victim.

On the contrary, bullying and cyberbullying behavior have been associated with low experience of moral emotions such as empathy and sympathy (Perren \& GutzwillerHelfenfinger, 2012; Romera et al., 2019). Bullies report less guilt and shame compared with victims and bystanders (Mazzone et al., 2018; Pepler et al., 2008). Bullies, therefore, appear to experience fewer moral emotions, although they have no difficulty interpreting these situations as morally wrong (Gini et al., 2011). Specifically, it has been observed that bullies show adequate levels of moral comprehension, although they show less compassion, and, they exhibit moral justifications with less responsibility than people who defend victims (Gini et al., 2011). In this sense, Bandura (2016) proposed that people use moral disengagement as a strategy for socio-cognitive reconstruction to justify immoral and violent actions. For example, moral disengagement has been related to passive behavior from bystanders faced with bullying (Gini et al., 2020), as well as to high levels of bullying behavior over time (Teng et al., 2020). Therefore, moral disengagement should promote a low experience or avoidance of moral emotions such as empathy, sympathy, and guilt from bullies and bystanders, emotions which would otherwise contribute to awareness of the impact of violence on others (Malti et al., 2020; Sznycer, 2019). Likewise, pride can also promote moral disengagement and justification of harmful behaviors toward others in bullies if linked to a lack of empathy (Wachs, 2012).

In summary, the studies highlighted the importance of moral emotions such as empathy, sympathy, and guilt in understanding the consequences for victims of violence, and therefore, for the reduction of aggressive behavior and the promotion of prosociality. However, there is a gap in knowledge regarding the roles of other moral emotions, which have been studied in other fields in adult populations. One of the best-known perspectives that have delved into the role of these emotions in moral judgment is the moral foundations theory (Graham et al., 2008, 2009). This theory comprises six innate and universal principles (care, fairness, authority, loyalty, sanctity, and liberty) that promote the development of moral judgment, always in accordance with social and cultural norms that determine the relevance of these principles in specific situations (Haidt, 2003). On this basis, the perception that one of these moral principles has been violated elicits specific emotions. For example, the view of a situation as unfair can elicit anger or the perception of poor care or lack of protection can elicit compassion towards someone (Graham et al., 2008). Keeping with these ideas, Haidt (2003) classified moral emotions into four families based on their orientation towards oneself or towards others, as well as the moral principles that elicit them: "other-condemning" (contempt, anger, and disgust), "self-conscious" (shame and guilt), "other-suffering" (compassion and sympathy), and "other-praising" emotions (gratitude, awe, elevation, and admiration).

More recently, some of these emotions, specifically gratitude, compassion, and awe, have been categorized as selftranscendent emotions since, from an evolutionary point of view, they are considered to fulfill a prosocial function of nurturing group relationships and the welfare of others (Stellar et al., 2017; Van Cappellen \& Rimé, 2014). In addition, these three emotions have been considered in many studies as traits or stable attitudes that would not only be elicited in specific moral situations but could also be constantly experienced (Stellar et al., 2017). Those individuals who are usually more compassionate or experience greater gratitude have also been observed to show more altruistic and prosocial behaviors (Stellar et al., 2017; Emmons \& McCullough, 2004). 
Literature associating self-transcendent dispositional emotions such as gratitude and compassion to bullying remains limited, although they may play an important role in the prevention of bullying. In fact, in a study by Rey et al. (2019), gratitude was observed to be negatively related to victimization in bullying situations. Another work by Gini et al. (2011) demonstrated that bullies have low levels of compassion compared to victims and bystanders. Furthermore, gratitude has been related to prosocial behavior (Mikulincer \& Shaver, 2010) and less violent behavior (Sun et al., 2019). In a recent study on early and late adolescents, gratitude was observed to promote prosocial behavior in bystanders of bullying situations (García-Vazquez et al., 2020). Similarly, compassion towards others was also linked to support, caring (Amutio et al., 2018; Stellar et al., 2017), and prosocial behavior in adolescents (Marshall et al., 2020).

In conclusion, although there is extensive literature on the relationship between bullying, sympathy, empathy, and guilt, the lack of research regarding the association between other moral emotions proposed in Haidt's (2003) taxonomy and bullying and prosocial behavior remains. It seems that selftranscendent emotions that are more focused on the wellbeing of others, such as gratitude and compassion, may play fundamental roles in the prevention of bullying. However, studies that link these emotions to bullying remain limited, particularly in the adolescent population (Rey et al., 2019).

\section{Dispositional and Situational Moral Emotions and their Assessment}

Scientific studies that assess emotions make a clear distinction between dispositional emotions, which are considered almost personality traits that remain stable over time, and situational emotions, which are experienced in specific social situations (Emmons et al., 2019; Emmons \& McCullough, 2004). This debate has also been highlighted in studies regarding the development of moral emotions (Malti et al., 2020).

Dispositional emotions represent the tendency to react to a specific emotion in concrete situations regardless of the context that may trigger that emotion (Spinrad \& Eisenberg, 2019). From a developmental psychology perspective, the study of dispositional emotions can help to shed light on the development of prosocial behavior (Spinrad \& Eisenberg, $2017,2019)$. For example, children with a high predisposition to experience guilt exhibit less antisocial behavior regardless of their empathy levels (Spinrad \& Eisenberg, 2019).

From a developmental point of view, many studies have dealt with the assessment of dispositional empathy and sympathy (Eisenberg, 2000). For example, a recent meta-analysis conducted by Zych et al. (2019) shows that a great variety of scales are used to measure empathy and sympathy in these studies, and many of them are self-reports that assess these emotions in a dispositional way. In addition, cognitive and affective components are evaluated separately. Cognitive empathy is usually closely related to sympathy because it involves taking a cognitive perspective on the emotional state of another person (Oriol et al., 2020a, 2020b). For their parts, gratitude, and compassion, usually defined as traits (Emmons \& McCullough, 2004), are assessed through questionnaires regarding daily life experience of these emotions (e.g., Amutio et al., 2018; Emmons \& McCCullough, 2004; Oriol et al., 2020a, 2020b). In addition, compassion and dispositional gratitude have been strongly related to the experience of altruism and prosociality (Bartlett \& DeSteno, 2006; Campos et al., 2013).

Moral emotions are often elicited in specific social situations where the transgression of a moral principle is perceived (Haidt, 2003; Malti et al., 2020). Accordingly, much of the international literature underscores the relevance of assessing emotions in specific contexts and according to the situation that elicited them (for a review, see Moors et al., 2013). The scales that assess emotional situations enquire about emotions experienced during specific situations or about the presence of emotions in concrete moments, considering the significance of these situations for individuals (Kahneman \& Deaton, 2010).

A wide variety of studies assessed moral emotions in bullying situations through vignettes that represent the emotions experienced by characters in victimization contexts (Malti et al., 2020; Romera et al., 2019). Many of these works aim to observe a phenomenon called "happy victimizer" to identify whether acts of violence in cases of bullying are perceived as "wrong," or not (for a review, see Krettenauer et al., 2008). Adolescents are asked to classify situations as good and bad and to assess the level of guilt they would feel in these scenarios (Krettenauer \& Eichler, 2006; Perren \& Gutzwiller-Helfeninger, 2012).

As mentioned above, empathy and sympathy have often been assessed dispositionally. Nevertheless, Thornberg et al. (2015) created a self-report scale to measure empathy, sympathy, and guilt that specifically inquiries about the experience of these emotions in bullying situations. To analyze the results obtained in their study, the authors created a global index of moral emotions and concluded that a low experience of these emotions was related to a high presence of bullying behavior and moral disengagement.

In summary, most of the studies have used different instruments to evaluate dispositional sympathy and empathy, as well as guilt and shame. However, there is a lack of self-report scales to assess other types of moral emotions in bullying situations. Other emotions within Haidt's (2003) taxonomy of moral emotions, such as "elevation" or "disgust," have proved relevant in moral situations; however, these emotions have not been studied in situations 
of adolescent bullying. For instance, "moral elevation," which belongs to the family of "other-praising emotions," implies a response that does not benefit oneself (Haidt, 2003) and promotes a strong desire to actively help others (Cusi et al., 2018; Thomson \& Siegel, 2017). Conversely, "moral disgust," which belongs to the "other-condemning" family, could protect social order from moral transgressions, promoting rejection of people who elicit disgust (Lee \& Ellsworth, 2013). The experience of moral emotions has specific consequences for the social situations where they are elicited and, therefore, to study other emotions such as "elevation" or "disgust" in specific bullying situations becomes relevant.

\section{Present Study}

In the literature, several studies on bullying and moral emotions focus on sympathy, guilt, shame, and pride (Romera et al., 2019). However, other emotions have not been considered, despite their possible relevance to understand how to encourage prosocial behavior in bullying situations and reduce bullying. Instruments to assess other emotions from the families proposed by Haidt (2003) are lacking. Our first study aimed to present the psychometric properties of two questionnaires for the assessment of two moral emotions (i.e., elevation and disgust) that may be relevant to prevention of bullying behavior and promote prosocial behavior in cases of bullying. Furthermore, our work may contribute to the scientific literature on relationships between the dispositional emotions of gratitude and compassion and prosocial behavior and bullying prevention. The following hypotheses were formulated: H1) The scales will present adequate psychometric properties of reliability and validity; $\mathrm{H} 2$ ) is divided in two hypotheses: H2a). A positive and significant relationship will be found between situational moral emotions (i.e., moral elevation and disgust) and prosocial behavior towards victims. H2b). A negative and significant relationship will be found between situational moral emotions and bullying behavior. H3) The dispositional emotions of gratitude and compassion will have a significant, positive relationship with prosocial behavior and a significant, negative relationship with bullying behavior.

Our second study aimed to complement some findings from the first one through a repeated measures design with two-time points (Time 1 [T1] and Time 2 [T2]) that allowed observing the prospective relationship between gratitude, bullying behavior, and prosocial behavior toward victims. Therefore, the following hypotheses were proposed: H1) Dispositional gratitude (T1) will have a positive prospective effect on prosocial behavior toward victims (T2); H2) Dispositional gratitude (T1) will have a negative prospective effect on bullying behavior (T2).

\section{Data Analysis}

To test the hypotheses of Study 1 (H1, H2, and H3), an exploratory factor analysis (EFA) and correlations between variables were performed. Then, a confirmatory factor analysis of the instruments using structural equation modeling (SEM) were conducted. The method used for these analyses was maximum likelihood through bootstrapping. The measurement and SEM models presented were also calculated with analysis of moment structures (AMOS).

To test the hypotheses of Study 2 (H1 and H2), a Kolmogorov-Smirnov test was used to analyze variable distributions. Since distributions were not normal, maximum likelihood estimation was used to produce unbiased parameters (Straatmann et al., 2018). Comparisons between $\mathrm{T} 1$ and $\mathrm{T} 2$ were performed using the Wilcoxon Rank Compared Test to evaluate differences between mean ranks over time from $\mathrm{T} 1$ to $\mathrm{T} 2$.

Likewise, a cross-lagged multivariate SEM model was performed to indicate whether gratitude at $\mathrm{T} 1$ predicted prosocial behavior and/or bullying at T2. Following the guidelines of de Jonge et al. (2001), two SEM models were used to assess this relationship:

(1) A stability model without cross-lagged structural paths, and

(2) A model with cross-lagged structural paths from gratitude at Time 1 over prosocial behavior and bully behavior at Time 2.

For all SEM models, indicators of model fit statistics were provided, namely, Comparative Fit Index (CFI), TuckerLewis Index (TLI) (satisfactory values close to or above 0.90), and Standardized Root Mean Square ResidualRMSEA (satisfactory values below or close to 0.08). Chisquare difference tests were used to assess models (Kline, 2005). All statistical analyses were conducted in AMOS v. 23 and SPSS v.22.

\section{Study 1}

The objective of this study was two-fold: 1) To validate two scales for the situational moral emotions elicited in bullying situations (elevation and moral disgust) and 2) To examine the relationships between dispositional and situational moral emotions and prosocial behavior toward victims, and bullying behavior.

\section{Method}

\section{Sample}

The sample was composed of 644 Chilean students from four secondary schools in Santiago, Chile. Students were 
attending their first to the fourth year of Compulsory Secondary Education in accordance with the Chilean educational system. The age of the students ranged from 14-18 years $(M=15.6, D T=1.4)$. In terms of sex, $47.1 \%$ of the sample were males and $52.7 \%$ females. Informed consent from guardians and informed assent from students were collected following the guidelines of the Declaration of Helsinki and its later amendments for research involving human subjects. All ethical aspects of data collection were reviewed and approved by the ethics committee of Universidad Andres Bello (Chile).

First, the principals were contacted. Then, the guardians were informed regarding the scope of the study and the voluntariness of the same, and they signed the consent for data collection. Before responding to the questionnaires, students were also informed regarding the objective of the study and the voluntary nature of their participation. In addition, the students were informed that the data were only meant to be used for research purposes and that their identities would be protected. Students signed the informed assent prior to data collection as well.

\section{Procedure}

The selection of secondary schools was performed by contacting the principals, who were informed of the purpose of the study. The first data gathered from 70 participants was considered a pilot for item clean-up. This number was subsequently increased until the final sample size of 644 was obtained. The questionnaires were administered in the classroom for 10-15 min under the supervision of the class teacher.

\section{Measures}

Dispositional Compassion The questionnaire created by Shiota et al. (2006) covers different positive dispositional emotions. The five-item sub-scale on dispositional compassion was used (e.g., When I see someone hurt or in need, I feel a powerful urge to take care of them). The scale was assessed on a 7-point scale from (1) strongly disagree and (7) strongly agree. Cronbach's alpha was 0.88 for this sample.

Dispositional Gratitude The Chilean version (CarmonaHalty et al., 2015) of the dispositional gratitude questionnaire GQ- 6 by McCullough et al. (2002) was used. The original version of the scale comprises six items (e.g., When I look at the world, I don't see much to be thankful for. I am thankful to a wide variety of people); however, for this study, the two reverse-coded items were not used to facilitate the comprehension by adolescents. The items are scored on a 7-point Likert scale that ranges from 1 (strongly disagree) to 7 (strongly agree). Cronbach's alpha was 0.78 for this sample.

Traditional Bullying Behavior The scale developed and validated by Ortega-Ruiz et al. (2016) was used to measure bullying behavior. This scale is part of the European Bullying Intervention Project Questionnaire (EBIPQ), which assesses both victimization and traditional bullying behavior. For this study, its seven items on aggression, which refer to actions such as beating, insulting, threatening, stealing, using coarse language, excluding someone, and spreading rumors were used. All items are Likert-type, with a score from 0 to 4 , where 0 means "never" and 4 "always" for a 2 -month time interval. Cronbach's alpha was 0.76 .

Prosocial Behavior Toward Victims An adaptation of the Participant Roles Questionnaire (PRQ) by Salmivalli and Voeten (2004) was employed to measure this construct. The original version of the questionnaire inquiries about the roles of victim, aggressor, defender, and passive bystander. Based on the defender role in the original version, four items on the prosocial behavior of victim defenders were used (e.g., Tries to help students who normally suffer bullying situations - they are pushed, made fun of, or hit). Intervals comprise a Likert-type scale ranging from 0 to 4 , where 0 means "never" and 4 "always." Cronbach's alpha for this scale was 0.82 .

The scales for compassion and prosocial behavior toward victims considered in both studies had not been previously used on Spanish-speaking samples. Therefore, a direct and inverse translation process was conducted. A Spanish translator with command of the instrument's original language translated the questionnaires from English into Spanish. Subsequently, a second translator, an English native speaker with advanced command of Spanish and without access to the original questionnaires, performed the reverse translation.

Moral Elevation and Moral Disgust During Bullying Situations Due to the lack of scales that measure this construct in the international literature, two scales for capturing the experience of these two moral emotions were built. Different items were created based on the theory of moral emotions of Haidt (2003), namely, five items for moral elevation and six for moral disgust in bullying situations. Several researchers participated in their creation. All the members of the group also participated as expert judges to verify that the content of each question was suitable for the construct under assessment. To refine the understanding of the questions further, a group of nine adolescents was selected by convenience. Through a focus group, the adolescents' opinions were asked regarding the questions, and some words were changed to facilitate their understanding. 
Once the questions were defined, a first scale clean-up was conducted using an EFA comprising of 70 adolescents. The main components were analyzed, and items with factorial weights below 0.40 (see the Results section for more details and Table 1) were eliminated. Both scales resulted in four items each, which were measured through a Likerttype scale ranging from 0 ("Completely agree") to 7 ("Completely disagree").

The Moral Elevation during Bullying Situations Scale (MEBSC) asks students about the admiration they feel for people who undertake actions related to reporting bullying and defending victims (e.g., I feel admiration when I see a classmate helping another classmate who has suffered bullying). The scale presented a Cronbach's alpha of 0.79 and a McDonald's omega of 0.81 .

The Moral Disgust during Bullying Situations Scale (MDBSS) asks students about the level of disgust they experience in situations where other classmates are bullied or suffer injustice (e.g., I feel that it is unfair when bullying against a classmate happens). The scale presented a Cronbach's alpha of 0.82 and a McDonald's omega of 0.83 .

\section{Results}

\section{Psychometric Properties of the Scales for Elevation and Moral Disgust during Bullying Situations}

Once the first clean-up was made with the pilot sample, an EFA was conducted using half of the sample $(n=287)$.
The first test of matrix adjustment was carried out using the Kaiser-Meyer-Olkin (KMO) test and Bartlett's test of sphericity. The results showed good estimators for sample adequacy: moral elevation $(K M O=0.79$; test of sphericity $p=0.00)$, and moral disgust $(K M O=0.81$; test of sphericity $p=0.00$ ). The main components were analyzed to test whether all items corresponded to a same dimension, as well as to verify the factor weight of each item and the total explained variance.

Results showed a factor weight above 0.40 of the items of both scales (see Table 1). The total explained variance of MEBSC considering all items was $65 \%$, with an alpha of 0.79 and a McDonald's omega of 0.81. Regarding MDBSS, the total explained variance was $69 \%$, with an alpha of 0.82 and a McDonald's omega of 0.83 . Inter-items and totalitem correlations were calculated to determine the internal consistency of the questionnaire. All the correlations were significant and above 0.40 .

\section{Descriptive Analysis and Correlations}

To test convergent validity, correlations were performed between the two created scales, together with the dispositional emotions, gratitude and compassion, and prosocial behavior during bullying situations, as shown in Table 2 .

\section{Factor Structure through SEM Analysis}

Finally, with the other half of the sample $(n=287)$, confirmatory factor analyses (CFA) were performed for each

Table 1 Factor weight of items from the Moral Disgust and Moral Elevation scales and corrected item-total correlation

Moral Disgust in bullying situations

Ítems

1. I get upset when boys or girls from my high school are beaten or insulted / Me molesta ver cuando pegan o insultan a otro chico o chica del liceo

2. I get angry when a classmate feels bad because he or she suffered bullying/ Me enfada que algún compañero o compañera se siente mal porque ha sufrido acoso escolar

3. I feel that it is unfair when bullying against a classmate happens / Siento que es injusto cuando se producen situaciones de acoso escolar contra un compañero o compañera /

4. I feel upset that there is violence between classmates at school/ Me disgusta que haya violencia entre compañeros en la escuela

Moral Elevation in bullying situations

ítems

1. I feel admiration when I see a classmate helping other classmate who has suffered bullying / Siento admiración cuando veo que un compañero ayuda a otro compañero cuando ha sufrido acoso escolar

2. I admire classmates who report bullying to adults so they can do something about it/ Admiro a los compañeros que denuncian las situaciones de acoso escolar a los adultos para que estos hagan algo

3.I really appreciate classmates who are kind to other classmates and avoid violence at school / Valoro mucho a los compañeros que son amables con los demás compañeros y evitan la violencia dentro de la escuela

4. I feel that I would like to be like my classmates that do not spread rumours about other classmates because they know that that will make them feel bad/ Siento que me gustaría ser como los compañeros que evitan difundir rumores sobre otros compañeros o compañeras porque saben que les harán sentir mal
Factor Weight Ítem-Total

$.69 \quad .83$

$.48 \quad .73$

.71

.80

.62

Factor Weight Ítem-Total

$.71 \quad .82$

.78

.86

.65

.76

.50

.72 
scale, with the objective of confirming the factor solution obtained in the EFA of each questionnaire. The adjustment indexes of the four-item questionnaire on moral disgust were adequate: $\left(\chi^{2}=38.010 ; \chi 2 / g l: 2.1 ; T L I=0.96, C F I=0.96\right.$, $R M S E A=0.04)$. Adequate adjustment indexes were also observed for the moral elevation scale: $(\chi 2=53.362 ; \chi 2 / \mathrm{gl}$ : $1.02 ; T L I=0.97, C F I=0.98, R M S E A=0.01)$.

\section{Relationship Between Moral Emotions, Prosocial Behavior toward Victims and Bullying Behavior}

First, a measurement model was calculated considering all the variables in the model, which yielded an adequate adjustment: $\left(\chi^{2}=437.464 ; \chi^{2 / g l}: 2.9 ; T L I=0.91, C F I=0.91\right.$, $R M S E A=0.06)$. Subsequently, SEM was computed controlling for sex and age to test the relationship between situational moral emotions and prosocial behavior toward victims. The model showed an adequate adjustment: $(\chi 2=439.185$; $\chi 2 / g l: 2.9 ; T L I=0.91, C F I=0.91, R M S E A=0.06)$. All the direct effects observed were significant. Moral elevation had a stronger positive effect on prosocial behavior toward victims $(B=0.33, p<0.01)$ and a stronger negative effect on bullying behavior $(B=-0.22, p<0.05)$ than moral disgust (see Fig. 1).

\section{SEM Model Considering Dispositional and Situational Emotions}

A second SEM was calculated to measure the effect after including the dispositional emotions gratitude and compassion. Again, sex and age were controlled for in the model, which showed adequate adjustment $\left(\chi 2=495.789 ; \chi^{2 / g l}\right.$ : 3.5; $T L I=0.92, C F I=0.93, R M S E A=0.06)$. As observed in the indirect effects of Table 3, gratitude and compassion on prosocial behavior towards victims were significant.
Table 2 Means, standard deviation and correlations between all the variables

\begin{tabular}{lllllllll}
\hline Variable & & $\mathrm{M}$ & $\mathrm{SD}$ & 1 & 2 & 3 & 4 & 5 \\
\hline 1. Moral Admiration & 5.7 & 1.3 & & & & & \\
2. Moral Disgust & 5.8 & 1.3 & $.60^{* *}$ & & & & \\
3. Gratitude & 4.6 & .98 & $.39^{* *}$ & $.36^{* *}$ & & & \\
4. Compassion & 3.3 & .67 & $.70^{* *}$ & $.58^{* *}$ & $.49^{* *}$ & & \\
5. Prosocial Behavior & 2.6 & 83 & $44^{* *}$ & $.40^{* *}$ & $.52^{* *}$ & $.58^{* *}$ & & \\
6. Bullying Behavior & 1.4 &. .41 &.$-31^{* *}$ & $-27^{* *}$ & $-13^{* *}$ & $-27^{* *}$ & $-23^{* *}$ & \\
\hline
\end{tabular}

${ }^{*} p<.05 * * p<.01$

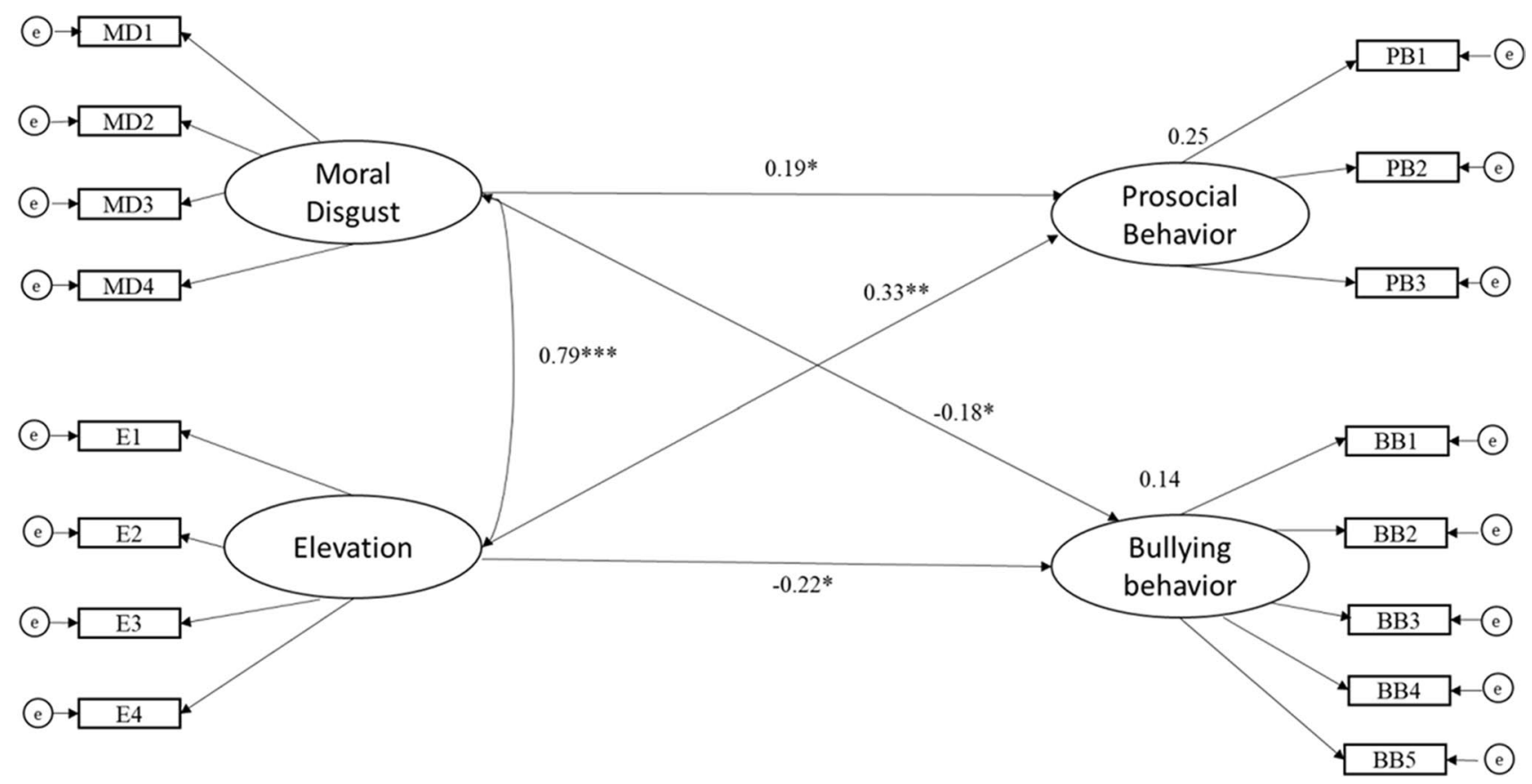

Fig. 1 SEM model considering the relationship between situational moral emotions and prosocial and bullying behavior 
Conversely, moral disgust and moral elevation only had significant effects on bullying behavior.

\section{Discussion}

The aim of Study 1 was to fill the gap regarding the lack of instruments to assess other moral emotions beyond those typically studied, such as empathy, sympathy, pride, and guilt. Two instruments were created to evaluate elevation and moral disgust, and their psychometric properties were tested. Furthermore, it was expected to clarify our understanding of the relationships between these two situational emotions (elevation and moral disgust) and dispositional emotions (compassion and gratitude) and prosocial and bullying behaviors.

Consistent with first hypothesis, the psychometric properties of both situational emotion scales were adequate. The reliability of both scales measured by Cronbach's alpha and McDonald's omega were around 0.80 , which is an acceptable value. In addition, EFA showed a single-factor solution for both questionnaires that was confirmed by the CFAs of both scales, which also showed adequate adjustment. The moral emotions of disgust and elevation showed positive and significant relationships with the dispositional emotions of gratitude and compassion and with prosocial behavior toward victims during bullying situations. Conversely, they showed significant negative relationships with bullying behavior.

Confirming the second hypothesis, both situational moral emotions of disgust and elevation showed a positive and significant effect on prosocial behavior toward victims and a negative effect on bullying behavior. These results confirm the relevance of disgust for the promotion of rejection and avoidance of transgressions against the moral norm in bullying situations (Haidt, 2003). Thus, disgust appears to

Table 3 SEM path coefficients of dispositional and situational moral emotions on prosocial and bullying behavior

\begin{tabular}{llll}
\hline & Path coeff & \\
Moral Disgust & $-->$ & $\begin{array}{l}\text { Prosocial Behavior toward } \\
\text { victims }\end{array}$ & 0.02 \\
\hline Moral Elevation & $-->$ & $\begin{array}{l}\text { Prosocial Behavior toward } \\
\text { victims }\end{array}$ & 0.10 \\
Gratitude & $-->$ & $\begin{array}{l}\text { Prosocial Behavior toward } \\
\text { victims }\end{array}$ & $0.25^{*}$ \\
Compassion & $-->$ & $\begin{array}{l}\text { Prosocial Behavior toward } \\
\text { victims }\end{array}$ & $0.58^{* * *}$ \\
Moral Disgust & $-->$ & $\begin{array}{l}\text { Bullying Behavior } \\
\text { Mollying Behavior }\end{array}$ & $-0.21^{*}$ \\
Gratitude & $-->$ & $\begin{array}{l}\text { Bullying Behavior } \\
\text { Bullying Behavior }\end{array}$ & $-0.34^{* *}$ \\
Compassion & $-->$ & Bulion & -0.08 \\
\hline
\end{tabular}

$\beta$, standardized path coefficient ${ }^{*} \mathrm{p}<0.05 ;{ }^{* *} \mathrm{p}<0.01 ;{ }^{* * *} \mathrm{p}<0.001$. make people retaliate against transgressors of the norm (Lee \& Ellsworth, 2013). In addition, this emotion could mobilize resources to ensure social order with a clear function of communicating moral intentionality (Sznycer, 2019). Rejection of bullying could also encourage students to support the bullied victims who directly suffer the transgression of the norm. These findings reinforce the idea observed in other studies that the experience of moral emotions, such as guilt or shame, reduces bullying behavior, but is less present in bullies (Mazzone et al., 2018; Pepler et al., 2008). Furthermore, this relationship is stronger for moral elevation, especially regarding prosociality towards the victim. Elevation is an emotion related to mobilization towards prosocial behavior (Thompson \& Siegel, 2017) that consequently promotes self-transcendence and common welfare (Stellar et al., 2017). Therefore, Study 1 findings indicate that this emotion may contribute not only to the decrease in bullying behavior but also to a greater predisposition to help the victims, as observed with other moral emotions, such as sympathy (Thornberg et al., 2015).

The results on the third hypothesis reinforce even more the relevance of transcendence emotions and specifically emotions such as dispositional gratitude and compassion in the prosocial behavior towards victims. Once included in the SEM model, situational moral emotions cease to have a significant effect on prosociality towards victims. According to the literature, dispositional gratitude appears as a stable tendency to be grateful under different circumstances and promotes positive relationships (Emmons et al., 2019). Therefore, from this perspective, the constant experience of gratitude could promote social integration and social support in adolescence (Marshall et al., 2020). In another vein, compassion as a trait is defined as caring about others and the willingness to help them (Stellar et al., 2017). Compassion from an evolutionary perspective promotes prosociality towards the in-group members (Amutio et al., 2018; Stellar et al., 2017). Likewise, it is also related to a decrease in unethical behaviors associated with moral disengagement (Yang et al., 2020). The results of this study confirm that compassion contributes to the appearance of prosocial behaviors towards victims during bullying situations. From a developmental point of view, these outcomes emphasize the relevance that dispositional emotions may have in the development of affective-cognitive processes involved in prosocial behavior, as indicated in the studies by Spinrad and Eisenberg $(2017,2019)$.

Additionally, SEM results also show that in this model, which includes all the emotions (dispositional and situational), situational moral emotions have a significant negative relationship with bullying behavior as opposed to dispositional emotions. Therefore, situational moral emotions such as disgust and elevation appear to play an extremely significant role in the prevention of aggressive behaviors 
that transgress normal morality in bullying situations. However, dispositional emotions of self-transcendence, which are considered more stable over time, should contribute to more prosocial behavior in situations of violence. This in consistent with previous studies which have emphasized that both gratitude and dispositional compassion are key for the development of altruistic behaviors due to the satisfaction that people who habitually experience these emotions find in helping others (Emmons et al., 2019; Stellar et al., 2017).

In summary, Study 1 results constitute an advancement in the understanding of the relationship between previously poorly studied moral emotions, such as elevation and moral disgust, and dispositional emotions, such as compassion and gratitude, and bullying and prosocial behavior toward victims in an adolescent sample. The findings are relevant for improving bullying prevention programs and strategies. However, longitudinal studies are necessary in order to allow us to observe the prospective relationships between these variables. Study 2 is focused on being able to reduce this gap in the literature.

\section{Study 2}

The objective of Study 2 was to observe the prospective relationship between gratitude, bullying behavior, and prosocial behavior toward victims.

\section{Method}

\section{Sample}

Initially, 333 Peruvian students from private schools, aged 10-15 years, participated in this study. At Time 1 (T1), the objective, scope, and voluntariness of the study were communicated to the students' guardians, who signed an informed consent authorizing their children to participate in the study. Students were also asked to sign an informed assent to participate in the study prior to questionnaire completion. The virtual document specified that answers would be confidential and that only the research team could identify the information through a code, but without specifying the student's name. Likewise, students were informed that they could stop answering the questionnaire whenever they deemed it convenient and that the survey would have no consequences on their grades. All the procedures were designed following the ethical principles of the Declaration of Helsinki and its latter amendments for research involving human subjects. The study was approved by the ethics committee of Universidad Continental (Peru).

At Time 2 (T2), the same protocol was applied. Of the students who completed the baseline, 29 (8.1\%) did not take apart in Time 2 data collection because they did not hand over the informed consent or did not attend school the day of the survey. Furthermore, 304 cases responded at both the baseline and the second time of data collection. Finally, cases with missing values above $10 \%$ at both times were discarded.

The final sample consisted of 235 Peruvian students aged $11-14$ years $(M=12.5, D T=0.9)$. An imputation process of the maximum likelihood estimation with missing cases was used. Specifically, $5 \%$ of the data points were deleted. This analysis has demonstrated to be the most pragmatic approach for missing data estimation in SEM (Enders, 2001). Thus, statistical analyses were carried out with 235 students in both waves.

\section{Procedure}

These data are part of a pilot program for the development of socioemotional skills in private educational institutions from Lima Metropolitana (KUSI program). A longitudinal data collection with two measures (T1 and T2) 7 months apart from each other was performed. For the application of the survey, which is part of the project's baseline, the research team reached out to the school management team, who informed the students' guardians regarding the implementation of the program and the administration of the survey.

Additionally, a protocol was used to refer students to the Psychology Department in case any of them presented distress signals during the administration of the questionnaires. The protocol was created based on the guidelines for studies on human beings provided by the Declaration of Helsinki.

\section{Measures}

Dispositional Gratitude As in Study 1, the dispositional gratitude scale by McCullough et al. (2002) was used to assess dispositional gratitude (see example items in Study 1). The Cronbach's alpha for this scale was 0.85 and 0.78 for T1 and T2, respectively. The items consisted of a 7-point Likert scale ranging from 1 (strongly disagree) to 7 (strongly agree).

Traditional Bullying Behavior As in Study 1, the bullying behavior scale by Ortega-Ruiz et al. (2016) was employed (see Study 1). This scale is part of EBIPQ. Cronbach's alpha was 0.68 and 0.65 for $\mathrm{T} 1$ and $\mathrm{T} 2$, respectively.

Prosocial Behavior Toward Victims As in Study 1, PRQ by Salmivalli and Voeten (2004) was used. The scale contains 4 items with response intervals from 0 to 4 , where 0 means "never" and 4 "always." The Cronbach's alpha of this scale was 0.78 for $\mathrm{T} 1$ and 0.77 for $\mathrm{T} 2$. 


\section{Results}

The distribution of the variables selected for the model is in Table 4. Globally, gratitude is observed to present higher levels than prosocial behavior for both Time1 and Time 2. Differences by gender were only found in the bullying behavior indicator for $\mathrm{T} 2$, where males reported higher scores in this variable than females $\left(M_{\text {boyt } 2}=0.27, M_{\text {girlt } 2}=0.14, p=0.03\right)$. No significant differences were seen in the rest of the variables analyzed. Regarding the changes between times (from $\mathrm{T} 1$ to $\mathrm{T} 2$ ), results showed that, at the global level, the indicators increased over time, with the only significant change being that of bullying behavior between both times.

Table 4 Distribution and comparison of variables at both times (T1 and T2)

\begin{tabular}{lllll}
\hline & Minimum & Maximum & Mean & SD \\
\hline Time 1 & & & & \\
Gratitude & 0 & 4 & 3.41 & 0.62 \\
Bullying Behavior & 0 & 2 & 0.16 & 0.27 \\
Prosocial behavior & 0 & 4 & 2.81 & 0.89 \\
Time 2 & & & & \\
Gratitude & 0 & 4 & 3.35 & 0.55 \\
Bullying Behavior & 0 & 2 & 0.20 & 0.32 \\
Prosocial behavior & 0 & 4 & 2.74 & 0.82 \\
Comparation T2- & & & & \\
$\quad$ T1 & & & & \\
& Mean difference & & P value** \\
Gratitude & 0.05 & & n.s & \\
Bullying Behavior & 0.04 & \multicolumn{3}{c}{ n.s } \\
Prosocial behavior & 0.07 & & \\
\hline
\end{tabular}

Table 5 presents the correlations of the variables for both $\mathrm{T} 1$ and $\mathrm{T} 2$. The correlations for each variable at $\mathrm{T} 1$ and $\mathrm{T} 2$ are significant and positive. For T1, bullying behavior was negatively associated with prosocial behavior $(r=-0.15, p<0.05)$ and gratitude $(r=-0.17, p<0.05)$, while gratitude and prosocial behavior correlated positively ( $r=0.43, p<0.05$ ). For T2, bullying behavior was negatively and significantly associated with gratitude $(r=-0.22, p<0.05)$, and the correlation between gratitude and prosocial behavior was positive and significant $(r=0.38, p<0.05)$. Likewise, the alpha coefficient estimator for each index for both $\mathrm{T} 1$ and $\mathrm{T} 2$ was reported (Table 5).

As the first step of SEM with maximum likelihood estimation, a baseline model was built with autoregressive paths for each variable from the T1 and T2 models. In this first model, data reported acceptable adjustment indexes after covariation was calculated for gratitude and prosocial behavior at $\mathrm{T} 1$ and $\mathrm{T} 2: \chi^{2}=471.023, \chi 2 / g . l .=1.91$, $R M S E A=0.07, C F I=0.90, T L I=0.90$. Autoregressive coefficients were 0.47 for gratitude $(p<0.01), 0.53$ $(p<0.05)$ for bullying behavior, and $0.49(\mathrm{p}<0.01)$ for prosocial behavior.

The cross-lagged multivariate SEM model also shows satisfactory adjustment indexes: $\chi^{2}=464.986$, $\chi^{2} / \mathrm{g} .1 .=1.89, R M S E A=0.06, T L I=0.90, C F I=0.91 . \mathrm{In}$ this model, the coefficients reported were: gratitude $\mathrm{T}_{\mathrm{T} 1}$ to gratitude $_{\mathrm{T} 2}(B=0.48, p<0.01)$, bullying behavior ${ }_{\mathrm{T} 1}$ to bullying behavior ${ }_{\mathrm{T} 2}(B=0.48, p<0.05)$, prosocial behavior $_{\mathrm{T} 1}$ to prosocial behavior $\mathrm{T} 2_{2}(B=0.48, p<0.05)$. Finally, gratitude $_{\mathrm{T} 1}$ to bullying behavior $\mathrm{T} 2(B=0.48, p<0.05)$ and gratitute $_{\mathrm{T} 1}$ to prosocial behavior ${ }_{\mathrm{T} 2}(B=0.14, p>0.05)$. Figure 2 presents these results.

**Wilcoxon Rank Compared Test

Table 5 Correlations with confidence intervals among all the variables of the model (T1 and $\mathrm{T} 2$ )

\begin{tabular}{|c|c|c|c|c|c|}
\hline Variable & 1 & 2 & 3 & 4 & 5 \\
\hline \multicolumn{6}{|l|}{ 1. Bullying behavior $\mathrm{t} 1$} \\
\hline 2. Bullying behavior $\mathrm{t} 2$ & $\begin{array}{l}.42 * * \\
{[.30, .52]}\end{array}$ & & & & \\
\hline 3. Prosocial behavior $\mathrm{t} 1$ & $\begin{array}{l}-.15^{*} \\
{[-.28,-.02]}\end{array}$ & $\begin{array}{l}-.13 \\
{[-.25, .01]}\end{array}$ & & & \\
\hline 4. Prosocial behavior $\mathrm{t} 2$ & $\begin{array}{l}-.06 \\
{[-.20, .07]}\end{array}$ & $\begin{array}{l}-.13 \\
{[-.26, .00]}\end{array}$ & $\begin{array}{l}.40 * * \\
{[.28, .50]}\end{array}$ & & \\
\hline 5. Gratitude $\mathrm{t} 1$ & $\begin{array}{l}-.19 * * \\
{[-.31,-.06]}\end{array}$ & $\begin{array}{l}-.23 * * \\
{[-.35,-.10]}\end{array}$ & $\begin{array}{l}.43 * * \\
{[.32, .53]}\end{array}$ & $\begin{array}{l}.24 * * \\
{[.11, .36]}\end{array}$ & \\
\hline 6. Gratitude $\mathrm{t} 2$ & $\begin{array}{l}-.17 * \\
{[-.30,-.04]}\end{array}$ & $\begin{array}{l}-.22 * * \\
{[-.34,-.09]}\end{array}$ & $\begin{array}{l}.26^{* *} \\
{[.13, .38]}\end{array}$ & $\begin{array}{l}.38 * * \\
{[.26, .48]}\end{array}$ & $\begin{array}{l}.40 * * \\
{[.28, .51]}\end{array}$ \\
\hline
\end{tabular}

Values in square brackets indicate the $95 \%$ confidence interval for each correlation. The confidence interval is a plausible range of population correlations that could have caused the sample correlation (Cumming, 2014). * indicates $p<.05$. ** indicates $p<.01$ 


\section{Discussion}

This study aimed to delve into some of the findings observed in Study 1 through a repeated measures design with two-time points, which allowed us to observe the prospective relationships between dispositional gratitude and aggressive and prosocial behavior.

The results showed that gratitude is prospectively related in a positive and significant way to prosocial behavior toward victims (H1). Therefore, results confirm the relevance of gratitude as a dispositional emotion to the development

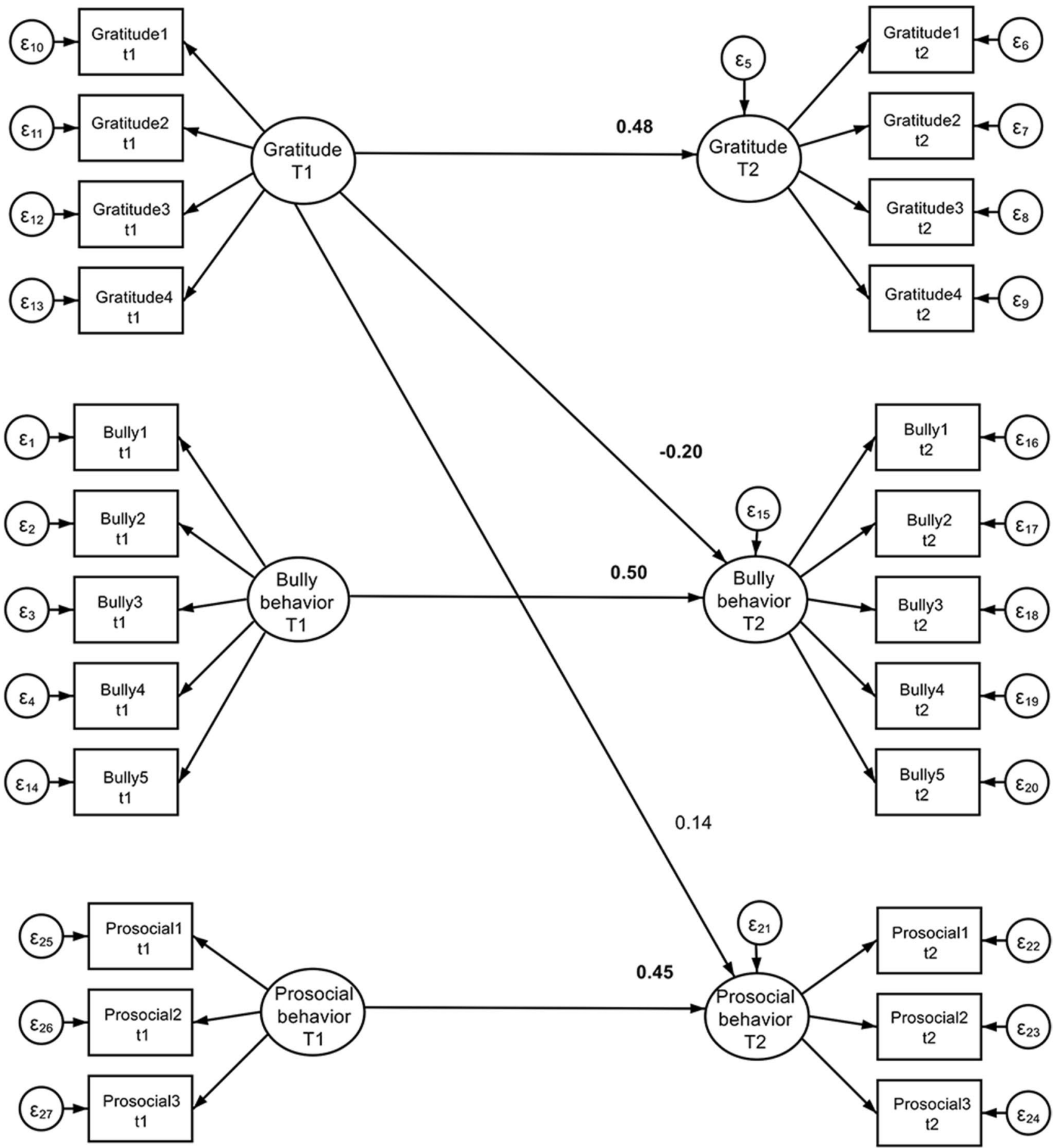

Fig. 2 Multivariate structural model. Coefficients shown are standardized. Significant coefficients are in bold $(p<0.05)$ 
of prosocial behavior (Emmons et al., 2019; Emmons \& McCullough, 2004) and in specific situations of moral transgression such as bullying. Consequently, promoting emotions that can behave as stable attitudes or traits from early ages is fundamental to prevent these forms of peer violence (Romera et al., 2019; Spinrad \& Eisenberg, 2017). Usually, people who present high dispositional gratitude offer more support to people who need it (Emmons \& McCullough, 2004), build new interpersonal relationships easily, and maintain them over time (Gordon et al., 2012). According to our results, this may encourage them to offer help and support to victims of bullying.

As for the second hypothesis, results also showed that gratitude is negatively and significantly related to bullying behavior. Aggressors in bullying cases often present externalizing problems and deficiencies in socioemotional skills (Zych et al., 2018). Nevertheless, people with high dispositional gratitude have higher levels of well-being and positive affectivity (Emmons et al., 2019; Oriol, et al., 2020a, 2020b). Thus, gratitude could contribute to the prevention of violent behavior through improvement in people's personal resources. According to the broaden-and-build theory developed by Fredrickson (2004), dispositional gratitude is an emotion that promotes the experience of constant positive affect and allows building long-lasting resources, which enhances the cognitive flexibility of individuals, making them more creative and socially integrated. Therefore, gratitude is considered a positive psychological trait that helps individuals embrace a more positive vision of the world (Emmons et al., 2019).

In summary, our results indicate that dispositional gratitude is key for the prevention of bullying behavior during bullying situations and for the promotion of prosocial behavior towards victims. This fundamental role could be attributed to the fact that dispositional gratitude encourages affective and cognitive processes that allow people to see the benefits of helping others and therefore increasing altruistic behaviors (Emmons et al., 2019). This aspect is important if we consider that certain moral emotions such as affective empathy may lead to distress due to an over-identification with the emotional state of others (Oriol, et al., 2020a, 2020b). However, the constant expression of gratitude contributes to positive affection and satisfaction with the fact of showing altruistic behaviors (DeSteno, 2018), which makes this emotion strongly related to subjective well-being (Oriol, et al., 2020a, 2020b; Oriol, et al., 2020a, 2020b).

\section{General Discussion}

From the perspective of developmental psychology, one of the most basic aspects of bullying studies is to understand the role of moral emotions in its prevention (Romera et al.,
2019; Zych et al., 2019). The results of this research emphasize the fundamental role of both self-transcendence dispositional emotions (emotions considered as traits or stable attitudes) and situational moral emotions (elicited in specific bullying situations) in their relationship with prosocial behaviors toward victims and bullying behavior. In Study 1, elevation and moral disgust were observed to contribute to more prosocial behaviors toward victims, while these two emotions were negatively related to bullying behavior. However, when self-transcendence dispositional emotions such as gratitude and compassion were included in the model, these two situational moral emotions continued to show a negative effect on bullying behavior and a positive and significant relationship with prosocial behavior.

These results reinforce the idea that self-transcendence dispositional emotions are relevant to the development of prosocial behavior and altruism in different moral situations, as indicated by previous studies (Stellar et al., 2017; Van Cappellen \& Rimé, 2014). Furthermore, unlike other moral emotions, they contribute to the development of affective and cognitive processes that allow us not only to understand the emotional states of others but to activate cognitive mechanisms for reducing distress (Chierchia \& Singer, 2016; Emmons et al., 2019).

Previous studies have shown that both gratitude and dispositional compassion are related to experiences of positive affect and satisfaction with helping others (for a review, see Stellar et al., 2017). Our results reinforce those from other studies developed by Spinrad and Eisenberg (2017, 2019), which defend the importance of experiencing emotions that encourage help and prosocial behavior from an early age and emphasize the relevant roles of cognitive and affective processes in the acquisition of strategies that allow a person reducing the distress experienced in situations of empathy towards others (Spinrad \& Eisenberg, 2019).

Many of the studies conducted with children and adolescents using this approach have focused mostly on empathy and sympathy, but little on transcendent dispositional emotions (e.g., Malti et al., 2020). The results of Study 1 and 2 provide incipient evidence regarding the positive influence of these dispositional emotions (i.e., gratitude and compassion) in the prevention of bullying. However, further research on these emotions is required. In addition, and according to our results, the experience of moral emotions such as moral disgust and elevation in specific bullying situations are negatively and significantly related to bullying behavior, probably because these behaviors are considered unfair and morally unacceptable (Lee \& Ellsworth, 2013). This is in line with the idea proposed by other authors such as Malti and Dys (2015), who have observed that other moral emotions like guilt, empathy, or sympathy promote a deeper understanding and rejection of the negative effects of aggressive behavior towards the victims. In fact, some studies regarding moral 
disengagement in adolescence show how bullies avoid the experience of moral emotions to cognitively justify aggression (Gini et al., 2020; Thornberg et al., 2015). Ours and other researchers' results reinforce the need to study these and other moral emotions of Haidt's theory (2003), which have not been widely considered in studies concerning adolescent bullying.

Study 2 shows a positive prospective effect between the dispositional emotion of gratitude and prosocial behavior towards victims and a negative effect on bullying behavior. Additionally, unlike in Study 1, the negative effect of gratitude over bullying in Study 2 is stronger than its positive effect on prosocial behavior towards the victim. From a developmental perspective, it should be noted that the experience of moral emotions and the capacity of awareness develop during childhood and adolescence (Malti \& Ongley, 2014; Malti, 2020). These results suggest the need for interventions and programs that focus on promoting gratitude to prevent bullying during adolescence. Nevertheless, it is also important that schools foster the experience of these types of dispositional emotions from an early age in order to generate prosocial behaviors that prevent the occurrence of violence in further stages (Spinrad \& Eisenberg, 2019).

Several studies on bullying show how a low experience of emotions such as sympathy, shame, or guilt during bullying episodes contributes to bullying behavior (e.g., Mazzone et al., 2018; Pepler et al., 2008; Romera et al., 2019). However, our results indicate that the experience of selftranscendent emotions in a dispositional way may be effective for children at early ages to show more care for others and develop tendencies towards altruistic and prosocial behaviors, which would prevent or reduce the occurrence of aggressive behaviors towards peers. Thus, the results of our Study 2 confirm, through repeated measures, other findings in this field, specifically, that dispositional gratitude was negatively related to lower levels of violence in cases of bullying (García-Vazquez et al., 2020) and positively associated with prosocial behavior (Mikulincer \& Shaver, 2010).

Following this perspective, from an evolutionary standpoint, gratitude appears to not only encourage children to build stable social bonds and strong social connections with others from an early age but also contribute to the satisfactory experience of altruistic behaviors (Stellar et al., 2017; Snycer, 2019). Thus, strengthening personal resources would prevent people from adopting behaviors that transgress the moral norm and enable them to resolve interpersonal conflicts in more adaptive and assertive ways (Emmons et al., 2019; Fredrickson, 2004).

\section{Limitations and Future Research Directions}

This work has several limitations. First, the two samples in this project were from two different countries (i.e., Chile and Peru), which may impact our ability to compare the results of both the studies and generalize them. In Study 1, the sample collection was cross-sectional. Therefore, it is not possible to attribute cause-effect relationships between variables. In Study 2, data from the same subjects were collected in two time periods; however, to establish causal relationships between variables, longitudinal studies, including three or more means across time, would be necessary, as suggested by various authors (e.g., Achenbach, 1978). Second, the sample is small; therefore, conducting longitudinal studies with a larger sample would be crucial. The sample in Study 1 was from public schools, while those in Study 2 attended private institutions. Thus, future studies should assess the relationship between these variables considering the type of school. Finally, the roles of the two dispositional transcendence emotions (i.e., gratitude and compassion) in bullying at different ages need to be studied in greater depth.

\section{Conclusions and Practical Implications}

The findings of our study suggest the need to continue delving into the role of other moral emotions, in addition to those usually studied in the field of bullying, i.e., sympathy, empathy, guilt, shame, and pride. From a developmental perspective, the relationship between dispositional emotions like gratitude and compassion, and prosocial behavior toward victims highlights the importance of incorporating these emotions into bullying studies. The affective-cognitive processes involved in these dispositional emotions appear to be fundamental for the prevention of bullying. However, more longitudinal and experimental studies are required for a much better understanding of the relationships between these emotions and bullying and bystander behavior.

There is a multiplicity of moral emotions that can be elicited in bullying situations. The negative relationship observed between elevation and moral disgust and bullying behavior in our study may indicate that these emotions can play an important role in bullying prevention programs and strategies. Hence, as with the experience of other moral emotions, future studies should focus on how these emotions are related to moral disengagement in adolescence. Finally, incorporating different strategies (e.g., mindfulness, acceptance-based techniques) that augment the experience of the studied dispositional and situational emotions in the prevention of bullying behaviors can enhance treatment effectiveness.

\section{Compliance with ethical standards}

In both studies, informed consent from guardians and informed assent from students were collected following 
the guidelines of the Declaration of Helsinki and its later amendments for research involving human subjects.

Funding Open Access funding provided thanks to the CRUECSIC agreement with Springer Nature.

\section{Declarations}

Conflict of Interests The authors declare that they have no conflict of interest.

Data Availability The datasets generated during the current study are available from the authors with the permission of the schools that participated in these studies upon reasonable request.

Code Availability Not applicable.

Open Access This article is licensed under a Creative Commons Attribution 4.0 International License, which permits use, sharing, adaptation, distribution and reproduction in any medium or format, as long as you give appropriate credit to the original author(s) and the source, provide a link to the Creative Commons licence, and indicate if changes were made. The images or other third party material in this article are included in the article's Creative Commons licence, unless indicated otherwise in a credit line to the material. If material is not included in the article's Creative Commons licence and your intended use is not permitted by statutory regulation or exceeds the permitted use, you will need to obtain permission directly from the copyright holder. To view a copy of this licence, visit http://creativecommons.org/licenses/by/4.0/.

\section{References}

Achenbach, T. M. (1978). Research in developmental psychology: Concepts, strategies and methods. Free Press.

Amutio, A., Pizarro, J. J., Basabe, N., Telletxea, S., \& Harizmendi, M. (2018). Propiedades psicométricas de la Escala de Compasión hacia los Demás [Psychometric properties of the Scale of Compassion towards Others]. Revista Latinoamericana De Psicología Positiva, 4, 24-37.

Arseneault, L. (2017). The long-term impact of bullying victimization on mental health. World Psychiatry, 16(1), 27-28. https://doi.org/ $10.1002 /$ wps. 20399

Bandura, A. (2016). Moral disengagement: How people do harm and live with themselves. Worth Publishers.

Barlett, C., \& Coyne, S. M. (2014). A meta-analysis of sex differences in cyber-bullying behavior: The moderating role of age. Aggressive Behavior, 40(5), 474-488. https://doi.org/10.1002/ab.21555

Barón, M. J. O., Bilbao, I. E., Urquijo, P. M. A., López, S. C., \& Jimeno, A. P. (2018). Moral emotions associated with prosocial and antisocial behavior in school-aged children. Psicothema, 30(1), 82-88. https://doi.org/10.7334/psicothema2016.143

Bartlett, M. Y., \& DeSteno, D. (2006). Gratitude and prosocial behavior: Helping when it costs you. Psychological Science, 17(4), 319-325. https://doi.org/10.1111/j.1467-9280.2006.01705.x

Campos, B., Shiota, M. N., Keltner, D., Gonzaga, G. C., \& Goetz, J. L. (2013). What is shared, what is different? Core relational themes and expressive displays of eight positive emotions. Cognition \& Emotion, 27(1), 37-52. https://doi.org/10.1080/02699931.2012. 683852
Carmona-Halty, M. A., Marín-Gutierrez, M., \& Belmar-Saavedra, F. (2015). Análisis psicométrico del Gratitude Questionnaire 6 (GQ-6) en población chilena [Psychometric analysis of gratitude questionnaire 6 (GQ-6) in Chilean population]. Universitas Psychologica, 14(3), 865-872. 10.11144/ Javeriana.upsy 14-3.apgq

Charalampous, K., Georgiou, S., Demetriou, C., Tricha, L., Nikiforou, M., \& Stavrinides, P. (2020). Comparing short-term growth in traditional and cyber forms of bullying in early and mid-adolescent students. European Journal of Developmental Psychology, 18(3), 412-428. https://doi.org/10.1080/17405629.2020.1798754

Chierchia, G., \& Singer, T. (2016). The neuroscience of compassion and empathy and their link to prosocial motivation and behavior. In J. C. Dreher \& L. Tremblay (Eds.), Decision neuroscience: An integrative approach (pp. 247-257). Elsevier.

Cook, C. R., Williams, K. R., Guerra, N. G., Kim, T. E., \& Sadek, S. (2010). Predictors of bullying and victimization in childhood and adolescence: A meta-analytic investigation. School Psychology Quarterly, 25(2), 65-83. https://doi.org/10.1037/a0020149

Currie, C., Zanotti, C., Morgan, A., Currie, D., de Looze, M., Roberts, C., Samdal, O., Smith, O. R. F., \& Barnekow, V. (2012). Social determinants of health and well-being among young people. Health Behaviour in School-aged Children (HBSC) study: International report from the 2009/2010 survey. World Health Organization. https://www.euro.who.int/en/publicatio ns/abstracts/social-determinants-of-health-and-well-beingamong-young-people.-health-behaviour-in-school-aged-child ren-hbsc-study

Cusi, O., Pizarro, J. J., Alfaro-Beracoechea, L., Vera-Calzaretta, A., González-Burboa, A., Carrera, P., \& Páez, D. (2018). Elevación o inspiración moral: Creación y validación de una escala de elevación en castellano [Moral elevation or inspiration: creation and validation of an elevation scale in Spanish]. Revista Latino-Americana de Psicología Positiva, 4, 38-56. Especial Monográfico.

de Jonge, J., Dormann, C., Janssen, P. P., Dollard, M. F., Landeweerd, J. A., \& Nijhuis, F. J. N. (2001). Testing reciprocal relationships between job characteristics and psychological well-being: A cross-lagged structural equation model. Journal of Occupational and Organizational Psychology, 74(1), 29-46. https://doi.org/10. 1348/096317901167217

de Oliveira, W. A., Caravita, S. C. S., Colombo, B., Donghi, E., da Silva, J. L., \& Silva, M. A. I. (2019). Self-justification processes related to bullying among Brazilian adolescents: A mixed methods study. Frontiers in Psychology, 10, 1086. https://doi.org/10.3389/ fpsyg.2019.01086

DeSteno, D. (2018). Emotional success: The power of gratitude, compassion, and pride. Houghton Mifflin Harcourt.

Eisenberg, N. (2000). Emotion, regulation, and moral development. Annual Review of Psychology, 51(1), 665-697. https://doi.org/ 10.1146/annurev.psych.51.1.665

Elgar, F. J., McKinnon, B., Walsh, S. D., Freeman, J., Donnelly, P. D., de Matos, M. G., Gariepy, G., Aleman-Diaz, A. Y., Pickett, W., Molcho, M., \& Currie, C. (2015). Structural determinants of youth bullying and fighting in 79 countries. Journal of Adolescent Health, 57(6), 643-650. https://doi.org/10.1016/j.jadohealth.2015. 08.007

Emmons, R. A., Froh, J., \& Rose, R. (2019). Gratitude. In M. W. Gallagher, \& S. J. Lopez (Eds.), Positive psychological assessment: A handbook of models and measures (pp. 317-332). American Psychological Association. https://doi.org/10.1037/0000138-020

Emmons, R. A., \& McCullough, M. E. (Eds.). (2004). The psychology of gratitude. Oxford University Press.

Enders, C. K. (2001). The impact of nonnormality on full information maximum-likelihood estimation for structural equation models with missing data. Psychological Methods, 6(4), 352-370. https:// doi.org/10.1037/1082-989X.6.4.352 
Flannery, D. J., Todres, J., Bradshaw, C. P., Amar, A. F., Graham, S., Hatzenbuehler, M., Masiello, M., Moreno, M., Sullivan, R., Vaillancourt, T., Le Menestrel, S. M., \& Rivara, F. (2016). Bullying prevention: A summary of the report of the National Academies of Sciences, Engineering, and Medicine: Committee on the biological and psychosocial effects of peer victimization: Lessons for bullying prevention. Prevention Science, 17(8), 1044-1053. https://doi.org/10.1007/s11121-016-0722-8

Fredrickson, B. L. (2004). The broaden-and-build theory of positive emotions. Philosophical Transactions of the Royal Society of London. Series B: Biological Sciences, 359(1449), 1367-1377. https://doi.org/10.1098/rstb.2004.1512

García-Vázquez, F. I., Valdés-Cuervo, A. A., \& Parra-Pérez, L. G. (2020). The effects of forgiveness, gratitude, and self-control on reactive and proactive aggression in bullying. International Journal of Environmental Research and Public Health, 17(16), 5760. https://doi.org/10.3390/ijerph17165760

Gini, G., Pozzoli, T., \& Hauser, M. (2011). Bullies have enhanced moral competence to judge relative to victims but lack moral compassion. Personality and Individual Differences, 50(5), 603-608. 10. 1016/j.paid.2010.12.002

Gini, G., Thornberg, R., \& Pozzoli, T. (2020). Individual moral disengagement and bystander behavior in bullying: The role of moral distress and collective moral disengagement. Psychology of Violence, 10(1), 38-47. https://doi.org/10.1037/vio0000223

Gordon, A. M., Impett, E. A., Kogan, A., Oveis, C., \& Keltner, D. (2012). To have and to hold: Gratitude promotes relationship maintenance in intimate bonds. Journal of Personality and Social Psychology, 103(2), 257-274. https://doi.org/10.1037/a0028723

Graham, J., Haidt, J., \& Nosek, B. A. (2009). Liberals and conservatives rely on different sets of moral foundations. Journal of Personality and Social Psychology, 96(5), 1029-1046. https://doi. org/10.1037/a0015141

Graham, J., Haidt, J., \& Rimm-Kaufman, S. E. (2008). Ideology and intuition in moral education. European Journal of Developmental Science, 2(3), 269-286. https://doi.org/10.3233/DEV-2008-2306

Haidt, J. (2003). The moral emotions. In R. J. Davidson, K. R. Scherer, \& H. H. Goldsmith (Eds.), Handbook of affective sciences (pp. 852-870). Oxford University Press.

Haidt, J. (2007). The new synthesis in moral psychology. science, 316(5827), 998-1002. https://doi.org/10.1126/science. 1137651

Hong, J. S., \& Espelage, D. L. (2012). A review of research on bullying and peer victimization in school: An ecological system analysis. Aggression and Violent Behavior, 17(4), 311-322. https://doi.org/ 10.1016/j.avb.2012.03.003

Hymel, S., \& Swearer, S. M. (2015). Four decades of research on school bullying: An introduction. American Psychologist, 70(4), 293-299. https://doi.org/10.1037/a0038928

Jungert, T., Holm, K., Iotti, N. O., \& Longobardi, C. (2020). Profiles of bystanders' motivation to defend school bully victims from a self-determination perspective. Aggressive Behavior, 47(1), 78-88. https://doi.org/10.1002/ab21929

Kahneman, D., \& Deaton, A. (2010). High income improves evaluation of life but not emotional well-being. Proceedings of the National Academy of Sciences, 107(38), 16489-16493. https://doi.org/10. 1073/pnas. 1011492107

Kline, R. B. (2005). Principles and practice of structural equation modeling (2nd ed.). Guilford Press.

Krettenauer, T., \& Eichler, D. (2006). Adolescents' self-attributed moral emotions following a moral transgression: Relations with delinquency, confidence in moral judgment and age. British Journal of Developmental Psychology, 24(3), 489-506. https://doi.org/ 10.1348/026151005X50825

Krettenauer, T., Malti, T., \& Sokol, B. W. (2008). The development of moral emotion expectancies and the happy victimizer phenomenon: A critical review of theory and application. European Journal of Developmental Science, 2(3), 221-235. https:// doi.org/10.3233/DEV-2008-2303

Lee, S. W., \& Ellsworth, P. C. (2013). Maggots and morals: Physical disgust is to fear as moral disgust is to anger. In K. R. Scherer, \& J. R. J. Fontaine (Eds.), Components of emotional meaning: A sourcebook. Oxford University Press.

Malti, T. (2020). Kindness: A perspective from developmental psychology. European Journal of Developmental Psychology, 18(5), 629-657. https://doi.org/10.1080/17405629.2020.1837617

Malti, T., \& Dys, S. P. (2015). A developmental perspective on moral emotions. Topoi, 34(2), 453-459. https://doi.org/10.1007/ s11245-013-9224-5

Malti, T., \& Latzko, B. (2010). Children's moral emotions and moral cognition: Towards an integrative perspective. New Directions for Child and Adolescent Development, 2010(129), 1-10. https://doi.org/10.1002/cd.272

Malti, T., \& Ongley, S. F. (2014). The development of moral emotions and moral reasoning. In M. Killen, \& J. Smetana (Eds.), Handbook of moral development (2nd ed., pp. 163-183). Psychology Press.

Malti, T., Ongley, S. F., Peplak, J., Chaparro, M. P., Buchmann, M., Zuffianò, A., \& Cui, L. (2016). Children's sympathy, guilt, and moral reasoning in helping, cooperation, and sharing: A 6-year longitudinal study. Child Development, 87(6), 1783-1795. https://doi.org/10.1111/cdev.12632

Malti, T., Peplak, J., \& Acland, E. (2020). Emotional experiences in moral contexts: Developmental perspectives. In L. A. Jensen (Ed.), The Oxford handbook of moral development: An interdisciplinary perspective (pp. 244-263). https://doi.org/10.1093/ oxfordhb/9780190676049.013.14

Malti, T., Zhang, L., Myatt, E., Peplak, J., \& Acland, E. L. (2019). Emotions in contexts of conflict and morality: Developmental perspectives. In Handbook of Emotional Development (pp. 543-567). Springer.

Marshall, S. L., Ciarrochi, J., Parker, P. D., \& Sahdra, B. K. (2020). Is self-compassion selfish? The development of self-compassion, empathy, and prosocial behavior in adolescence. Journal of Research on Adolescence, 30(Suppl 2), 472-484. https://doi. org/10.1111/jora. 12492

Mazzone, A., Camodeca, M., \& Salmivalli, C. (2018). Stability and change of outsider behavior in school bullying: The role of shame and guilt in a longitudinal perspective. The Journal of Early Adolescence, 38(2), 164-177. https://doi.org/10.1177/ 0272431616659560

Mazzone, A., Yanagida, T., Caravita, C. S., \& S., \& Strohmeier, D. . (2019). Moral emotions and moral disengagement: Concurrent and longitudinal associations with aggressive behavior among early adolescents. The Journal of Early Adolescence, 39(6), 839-863. https://doi.org/10.1177/0272431618791276

McCullough, M. E., Emmons, R. A., \& Tsang, J. (2002). The gratefull disposition: A conceptual and empirical topography. Journal of Personality and Social Psychology, 82, 112-127. https:// doi.org/10.1037/0022-3514.82.1.112

Mikulincer, M., \& Shaver, P. R. (2010). Does gratitude promote prosocial behavior? The moderating role of attachment security. In M. Mikulincer \& P. R. Shaver (Eds.), Prosocial motives, emotions, and behavior: The better angels of our nature (pp. 267-283). American Psychological Association. https://doi.org/ 10.1037/12061-014

Miranda, R., Oriol, X., Amutio, A., \& Ortúzar, H. (2019). Adolescent bullying victimization and life satisfaction: Can family and school adult support figures mitigate this effect? Revista De Psicodidáctica (english Ed.), 24(1), 39-45. https://doi.org/10. 1016/j.psicod.2018.07.001 
Modecki, K. L., Minchin, J., Harbaugh, A. G., Guerra, N. G., \& Runions, K. C. (2014). Bullying prevalence across contexts: A meta-analysis measuring cyber and traditional bullying. Journal of Adolescent Health, 55(5), 602-611. https://doi.org/10.1016/j. jadohealth.2014.06.007

Moore, S. E., Norman, R. E., Suetani, S., Thomas, H. J., Sly, P. D., \& Scott, J. G. (2017). Consequences of bullying victimization in childhood and adolescence: A systematic review and metaanalysis. World Journal of Psychiatry, 7(1), 60. https://doi.org/ 10.5498/wjp.v7.i1.60

Moors, A., Ellsworth, P. C., Scherer, K. R., \& Frijda, N. H. (2013). Appraisal theories of emotion: State of the art and future development. Emotion Review, 5(2), 119-124.

Oriol, X., Miranda, R., \& Amutio, A. (2019). Correlates of bullying victimization and sexual harassment: Implications for life satisfaction in late adolescents. The Journal of School Nursing. https://doi.org/10.1177/1059840519863845

Oriol, X., Miranda, R., Bazán, C., \& Benavente, E. (2020a). Distinct routes to understand the relationship between dispositional optimism and life satisfaction: Self-control and grit, positive affect, gratitude, and meaning in life. Frontiers in Psychology, 11, 907. https://doi.org/10.3389/fpsyg.2020.00907

Oriol, X., Unanue, J., Miranda, R., Amutio, A., \& Bazán, C. (2020b). Self-transcendent aspirations and life satisfaction: The moderated mediation role of gratitude considering conditional effects of affective and cognitive empathy. Frontiers in Psychology, 11, 2105. https://doi.org/10.3389/fpsyg.2020.02105

Ortega-Ruiz, R., Del Rey, R., \& Casas, J. A. (2016). Evaluar el bullying y el cyberbullying validación española del EBIP-Q y del ECIP-Q. Psicología Educativa, 22(1), 71-79. https://doi.org/10. 1016/j.pse.2016.01.004

Pepler, D., Jiang, D., Craig, W., \& Connolly, J. (2008). Developmental trajectories of bullying and associated factors. Child Development, 79(2), 325-338. https://doi.org/10.1111/j.1467-8624.2007. 01128.x

Perren, S., \& Gutzwiller-Helfenfinger, E. (2012). Cyberbullying and traditional bullying in adolescence: Differential roles of moral disengagement, moral emotions, and moral values. European Journal of Developmental Psychology, 9(2), 195-209. https://doi.org/10. 1080/17405629.2011.643168

Rey, L., Quintana-Orts, C., Mérida-López, S., \& Extremera, N. (2019). Being bullied at school: Gratitude as potential protective factor for suicide risk in adolescents. Frontiers in Psychology, 10, 662. https://doi.org/10.3389/fpsyg.2019.00662

Romera, E. M., Ortega-Ruiz, R., Rodríguez-Barbero, S., \& Falla, D. (2019). How do you think the victims of bullying feel? A study of moral emotions in primary school. Frontiers in Psychology, 10, 1753. https://doi.org/10.3389/fpsyg.2019.01753

Sainio, M., Veenstra, R., Huitsing, G., \& Salmivalli, C. (2011). Victims and their defenders: A dyadic approach. International Journal of Behavioral Development, 35(2), 144-151. https://doi.org/10.1177/ 0165025410378068

Salmivalli, C., \& Voeten, M. (2004). Connections between attitudes, group norms, and behaviour in bullying situations. International Journal of Behavioral Development, 28(3), 246-258. https://doi. org/10.1080/01650250344000488

Shiota, M. N., Keltner, D., \& John, O. P. (2006). Positive emotion dispositions differentially associated with Big Five personality and attachment style. The Journal of Positive Psychology, 1(2), 61-71. https://doi.org/10.1080/17439760500510833

Smokowski, P. R., \& Evans, C. B. R. (2019). Consequences of bullying in childhood, adolescence, and adulthood: An ecological perspective. Springer. https://doi.org/10.1007/978-3-030-20293-4_3

Spinrad, T. L., \& Eisenberg, N. (2017). Prosocial behavior and empathy-related responding: Relations to children's well-being. In M.
Robinson, \& M. Eid (Eds.), The happy mind: Cognitive contributions to well-being. Springer.

Spinrad, T. L., \& Eisenberg, N. (2019). Prosocial emotions. In V. LoBue, K. Pérez-Edgar, \& K. Buss (Eds.), Handbook of emotional development. Springer. https://doi.org/10.1007/ 978-3-030-17332-6

Stellar, J. E., Gordon, A. M., Piff, P. K., Cordaro, D., Anderson, C. L., Bai, Y., Maruskin, L. A., \& Keltner, D. (2017). Self-transcendent emotions and their social functions: Compassion, gratitude, and awe bind us to others through prosociality. Emotion Review, 9(3), 200-207. https://doi.org/10.1177/1754073916684557

Straatmann, V. S., Almquist, Y. B., Oliveira, A. J., Rostila, M., \& Lopes, C. S. (2018). Cross-lagged structural equation models for the relationship between health-related state and behaviours and body bullying in adolescence: Findings from longitudinal study ELANA. PloS One 13(1): e0191253. https://doi.org/10.1371/journ al.pone. 0191253

Sun, P., Sun, Y., Jiang, H., Jia, R., \& Li, Z. (2019). Gratitude and problem behaviors in adolescents: The mediating roles of positive and negative coping styles. Frontiers in Psychology, 10, 1547. https:// doi.org/10.3389/fpsyg.2019.01547

Sznycer, D. (2019). Forms and functions of the self-conscious emotions. Trends in Cognitive Sciences, 23(2), 143-157. https://doi. org/10.1016/j.tics.2018.11.007

Teng, Z., Bear, G. G., Yang, C., Nie, Q., \& Guo, C. (2020). Moral disengagement and bullying perpetration: A longitudinal study of the moderating effect of school climate. School Psychology, 35(1), 99-109. https://doi.org/10.1037/spq0000348

Thomson, A. L., \& Siegel, J. T. (2017). Elevation: A review of scholarship on a moral and other-praising emotion. The Journal of Positive Psychology, 12(6), 628-638. https://doi.org/10.1080/ 17439760.2016.1269184

Thornberg, R., Pozzoli, T., Gini, G., \& Jungert, T. (2015). Unique and interactive effects of moral emotions and moral disengagement on bullying and defending among school children. The Elementary School Journal, 116(2), 322-337. https://doi.org/10.1086/683985

Thornberg, R., Wänström, L., \& Hymel, S. (2019). Individual and classroom social-cognitive processes in bullying: A short-term longitudinal multilevel study. Frontiers in Psychology, 10, 1752. $10.3389 \% 2$ Ffpsyg.2019.01752

Ttofi, M. M., Bowes, L., Farrington, D. P., \& Lösel, F. (2014). Protective factors interrupting the continuity from school bullying to later internalizing and externalizing problems: A systematic review of prospective longitudinal studies. Journal of School Violence, 13(1), 5-38. https://doi.org/10.1080/15388220.2013. 857345

Van Cappellen, P., \& Rimé, B. (2014). Positive emotions and selftranscendence. In V. Saroglou (Ed.), Religion, personality, and social behavior (pp. 123-145). Psychology Press.

Van der Graaff, J., Carlo, G., Crocetti, E., Koot, H. M., \& Branje, S. (2018). Prosocial behavior in adolescence: Gender differences in development and links with empathy. Journal of Youth and Adolescence, 47(5), 1086-1099. https://doi.org/10.1007/ s10964-017-0786-1

Wachs, S. (2012). Moral disengagement and emotional and social difficulties in bullying and cyberbullying: Differences by participant role. Emotional and Behavioural Difficulties, 17(3-4), 347-360. https://doi.org/10.1080/13632752.2012.704318

Wolke, D., \& Lereya, S. T. (2015). Long-term effects of bullying. Archives of Disease in Childhood, 100(9), 879-885. 10.1136\%2Farchdischild-2014-306667

Yang, Y., Guo, Z., Wu, J., \& Kou, Y. (2020). Self-compassion relates to reduced unethical behavior through lower moral disengagement. Mindfulness, 11, 1424-1432. https://doi.org/10.1007/ s12671-020-01354-1 
Zeng, P., Wang, P., Nie, J., Ouyang, M., \& Lei, L. (2020). Gratitude and cyberbullying perpetration: The mediating role of self-compassion and moral disengagement. Children and Youth Services Review, 119, 105608. https://doi.org/10.1016/j.childyouth.2020.105608

Zych, I., Beltrán-Catalán, M., Ortega-Ruiz, R., \& Llorent, V. J. (2018). Social and emotional competencies in adolescents involved in different bullying and cyberbullying roles. Revista de Psicodidáctica, (English ed.), 23(2), 86-93. https://doi.org/10.1016/j.psicod.2017. 12.001

Zych, I., Farrington, D. P., \& Ttofi, M. M. (2019). Protective factors against bullying and cyberbullying: A systematic review of meta-analyses. Aggression and Violent Behavior, 45, 4-19. https:// doi.org/10.1016/j.avb.2018.06.008

Publisher's note Springer Nature remains neutral with regard to jurisdictional claims in published maps and institutional affiliations. 